\title{
Healthcare Encounters Group Identifier
}

National Cancer Institute

\section{Source}

National Cancer Institute. Healthcare Encounters Group Identifier. NCI Thesaurus. Code C123971.

A character or string that represents a healthcare encounters group. 